\section{The heat is on}

\section{A successor to the Kyoto Protocol on climate change must involve mandatory emissions caps.}

T alks about a climate accord to succeed the Kyoto Protocol when it expires in 2012 begin in earnest next week in Montreal. They will take place amid concerns that nations who backed the protocol are retreating from its central principle: the imposition of mandatory caps on greenhouse-gas emissions.

No national leader still in office is more strongly associated with the Kyoto agreement than Britain's prime minister, Tony Blair, and his recent pronouncements on Kyoto II have worried supporters of mandatory caps. In a series of speeches earlier this month, Blair made no mention of targets and echoed US President George W. Bush by stressing the role of technology development in cutting emissions. Blair also said that something "better and more sensitive" than the initial agreement was needed to convince major developing nations such as India and China, which do not have to limit emissions under the current protocol, to sign up to a new version.

That seems fair enough. But if European leaders such as Blair fail to insist on targets as part of Kyoto II, there is a danger that the entire exercise could become meaningless. Technology, in the shape of cleaner fossil-fuel power stations, renewable energy sources and perhaps nuclear power, ought to form an important element of nations' climate-change strategies. But these technologies need to be nurtured through financial incentives produced by mandatory caps and carbon-trading arrangements.

Following criticism of his initial remarks, Blair has been talking up targets again, stating that "targets, sensitively and intelligently applied over the right timeframe" are needed after 2012. But it will take remarkable ingenuity to bridge the chasm between developed countries, such as the United States and Australia, that have done

little to cut their own emissions, and developing ones, such as China and India, that want rich nations to act before they do.

That said, there are already ideas in circulation about how to bring on board all these parties, including the United States, where a new administration elected in 2008 may take a more constructive approach. Specific industrial sectors might, for example, be asked to accept targets. China might agree to set targets on its energyintensive cement industry, which has substantial greenhouse-gas emissions, in return for more technical support from overseas companies, who would earn credits that they could trade off against the emissions commitments at home. Similar schemes already operate on a small scale under the Kyoto Protocol.

Other sectors could be regulated on an international basis. Governments might agree to establish national targets on vehicle fuel emissions and efficiency, for example. This would offer nations the chance to sign

"The last thing the process needs is for nations already committed to emissions targets under Kyoto to turn their backs on them now."

up to agreements in sectors in which they know they can improve without losing their competitive advantage.

Working out how these ideas can be combined with the existing carbon-trading system will be an immense challenge. The last thing the process needs is for nations already committed to emissions targets under the original Kyoto protocol to turn their backs on them now. It was relatively painless for some nations - notably Britain and Germany - to meet tight Kyoto targets, because local events had sharply reduced emissions shortly after 1990, the baseline date against which the protocol's targets were set.

Now new circumstances, including greater electricity demand in southern Europe and steady economic growth, are making it harder for the European Union to stay within the Kyoto caps. Its leaders must redouble their efforts to restrict emissions and to vigorously pursue as strong a successor agreement as is practicable.

\title{
Life is what you make it
}

\section{This issue celebrates the emerging field of synthetic biology.}

1 ow's this for creativity? Take Escherichia coli bacteria. Transform them into light-sensitive organisms by fusing a photoreceptor from the cyanobacterium Synechocystis to a protein in the E. coli membrane. Make a film (in both senses) of such bacteria and use them to record an image with a resolution of 100 megapixels per square inch. For the result, see page 441. For other bio-widgets, see page 417.

Achieving this neat trick required researchers to engineer component parts of gene circuitry. This bottom-up engineering is often referred to as synthetic biology. It is indeed a type of biology: developing circuits that achieve what nature has evolved over eons is one way of gaining insight into what makes life tick. But it is also engineering, of a type quite different to the simple manipulation of bits of DNA to incorporate or knock out existing genes. This technology allows biological components, circuits and potentially replicating organisms to be developed from scratch, possibly based on different genetic codes from those found in the wild.

In this special issue on synthetic biology, some of the field's founding figures describe the technical challenges of such engineering (see page 443), review the scope and foundational principles of the discipline (page 449), and explore ways in which socially responsible synthetic biologists can gain public trust by focusing on safety (page 423).

"This technology allows
biological components,
circuits and potentially
replicating organisms to be
developed from scratch."

Last year we expressed the hope that synthetic biologists would act to engage with stakeholders (Nature 431, 613; 2004). Nature is pleased to highlight community thinking on such issues, and welcomes, and will participate in, stakeholder discussions at the second international meeting on synthetic biology at Berkeley next May. And finally, knowing that a graphic can help get the message across to a wider audience, we are delighted to publish a cartoon introduction to the field (www.nature.com/nature/comics/syntheticbiologycomic). 